\title{
The Mental Health of Ethnic Minority Youths in South Korea and Its Related Environmental Factors: A Literature Review
}

\author{
Yeeun Lee, Minji Lee, and Subin Park \\ Clinical Research Center, Mental Health Research Institute, National Center for Mental Health, Seoul, Korea
}

\begin{abstract}
Objectives: With increasing concerns for the rapidly growing minority population in South Korea, this literature review addressed a range of mental health risks among multiethnic youths (MY) in South Korea by 1) comparing mental health outcomes with those of native-born youths and 2) identifying multiple layers of relevant environmental factors, from family and school relationships to culture. Methods: We reviewed 54 studies that fulfilled specific inclusion criteria.

Results: Multiple common risk/protective factors, including family separation, family relationship quality, parental socioeconomic and mental health status, social relationships at school, and cultural acceptance, were noted.

Conclusion: In general, empirical evidence indicates that minority youths have relatively heightened risks for emotional and behavioral problems. Future studies must elucidate the complex interplay between multiple risk and protective factors and the long-term adaptation and mental health service utilization of MY.
\end{abstract}

Key Words: Ethnic minority youth; Mental health; Minority health; Adjustment.

Received: May 31, 2019 / Revision: June 17, 2019 / Accepted: June 18, 2019

Address for correspondence: Subin Park, Clinical Research Center, Mental Health Research Institute, National Center for Mental Health, 127 Yongmasanro, Gwangjin-gu, Seoul 04933, Korea

Tel: +82-2-2204-0108, Fax: +82-2-2204-0280, E-mail: subin-21@hanmail.net

\section{INTRODUCTION}

Cultural and ethnic diversity is a growing trend in contemporary societies due to global migration [1]. South Korea, once an ethnically homogeneous society, is also experiencing a burgeoning ethnic minority population, with an influx of foreign workers and immigrants through marriage [2]. In 2008, when the Multicultural Family Support Act was first implemented, the number of multicultural families in the national survey was 144000 , but this number increased to 330000 in 2017, suggesting that the number of multicultural families more than doubled over the past decade [3]. Although this change can help foster positive diversity, minority groups are, at best, often underrepresented and, at worst, discriminated against or socially excluded [4]. This is particularly the case for ethnic minority youths who are faced with the challagenges of multicultural identities.

According to the 2018 national census data, the highest proportion of multiethnic youths (MY) comprise children born in South Korea to a Korean and a foreign spouse [who mi-

This is an Open Access article distributed under the terms of the Creative Commons Attribution Non-Commercial License (https://creativecommons.org/licenses/by-nc/4.0) which permits unrestricted non-commercial use, distribution, and reproduction in any medium, provided the original work is properly cited. grated mostly from China or Southeast Asian countries (80.4\%)], followed by children born to foreign-born parents (12.8\%), and children born in a foreign country to foreign parent(s) who later immigrated to South Korea (6.8\%) [2]. Therefore, most MY in South Korea are 2.5 generation Korean-born youths, with one foreign-born parent. In addition to the stress of being part of an ethnic minority, including stress due to discrimination and issues about belonging and identity [5,6], MY may experience stress as a result of contact between the distinct culture of foreign parent(s) and the culture of the majority [7]. These sociocultural adversities could make MY vulnerable to mental health problems.

With the increasing MY concerns, recent studies have examined mental health outcomes in the Korean society. However, to our knowledge, no literature review has been conducted to integrate the empirical findings of these studies. Thus, the goal of the present review was to assess the mental health of MY by comparing it to that of native-born Korean youths (NKRY) in order to monitor the mental health status of MY and to systematically summarize the effect of various contextual variables on their mental health. By employing the Bronfenbrenner's ecological system model [8], which underlines the importance and influence of the child's own contextual 
surroundings, we also summarized findings on the influence of multiple layers of social environments on the mental health of MY, from the most proximal familial influences to the most distal school, community, and cultural influences.

\section{METHODS}

\section{Search and selection}

We searched for empirical research papers on mental adaptation among school-aged MY and NKRY, with a minimum sample size of 25. Articles were excluded if they 1) were qualitative or reviews, 2) were irrelevant to the main topic (e.g., physical health and school adaptation), or 3) used unpublished data (e.g., thesis/dissertation).

Articles written in the English and Korean languages (published up until March 2019) were searched systematically in five online databases (International journals: PubMed, Scopus, and Web of Science; Korean journals: DBPIA and RISS). The following key search terms were used: multiethnic youths (multicultural OR bicultural OR biethnic OR multiethnic) AND (children OR adolescent OR youth OR teenage) AND mental health (psychiatr* OR psycholog* OR mental OR psychosocial OR wellbeing OR adjustment OR adaptation OR protective factor OR risk factor OR vulnerability factor OR resilience OR emotion OR behavior OR behaviour) AND Korea (Korea OR Korean). The search strategy was adjusted for each database. Initially, 507 articles were identified. After excluding duplicates and irrelevant articles by reviewing the titles and abstracts, 54 articles were finally included (Table 1, Fig. 1).

\section{RESULTS}

\section{Mental health among multiethnic youths}

Mental health problems can be categorized into internalizing and externalizing problems. Case-control studies that compared internalizing problems in MY, notably, depression and anxiety symptoms, with those of NKRY, showed variations in relative prevalence or severity. No significant difference was noted in reports on the prevalence and severity of internalizing symptoms including depressive and anxiety symptoms and suicidal ideation [9-12]. In other studies, however, the prevalence or severity of depressive and anxiety symptoms and suicidal behaviors among MY was high [13-16], even after adjusting for other sociodemographic variables $[17,18]$. Inconsistent results across studies may be attributed to varying sample characteristics. For instance, one national representative study noted that the relative risk for internalizing problems in MY differed according to sex, such that a relatively high prevalence of mood symptoms and suicidal ideation was observed only among male, but not female, youths [14]. Additionally, when compared with native-born Korean children, teacher-rated anxiety and depressive symptoms were higher only among younger (8-10 years), but not in older, MY [15].

For more lethal symptoms, such as history of suicide attempts and hospitalization after a suicide attempt, the risk is two to three times higher among MY than among nativeborn adolescents, although a similar result was not obtained for suicidal ideations/plans $[10,12,19]$. This suggests that despite the lack of difference in the prevalence of suicidal ideations/plans between MY and NKRY, MY are more likely to attempt suicide, which warrants special attention. In addition to these clinical problems, young MY consistently re-

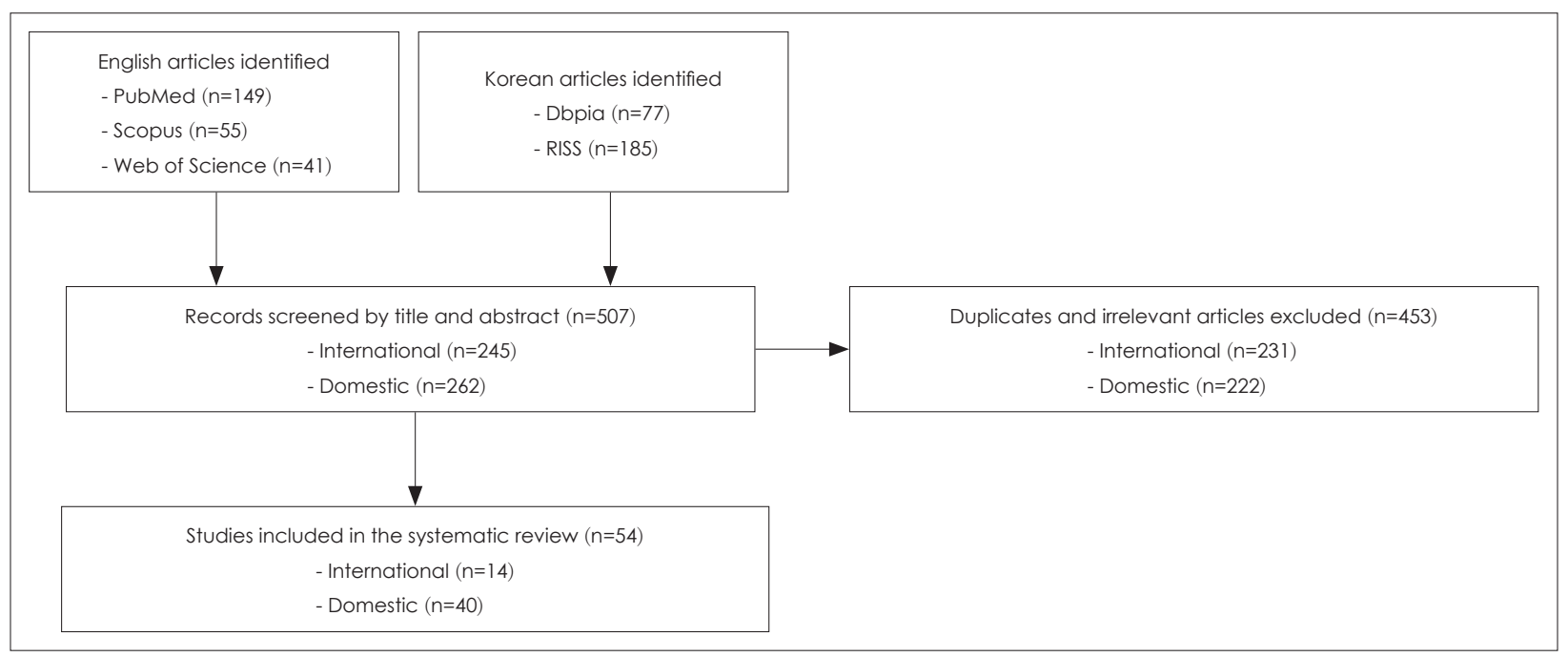

Fig. 1. Search strategy and article selection process. 


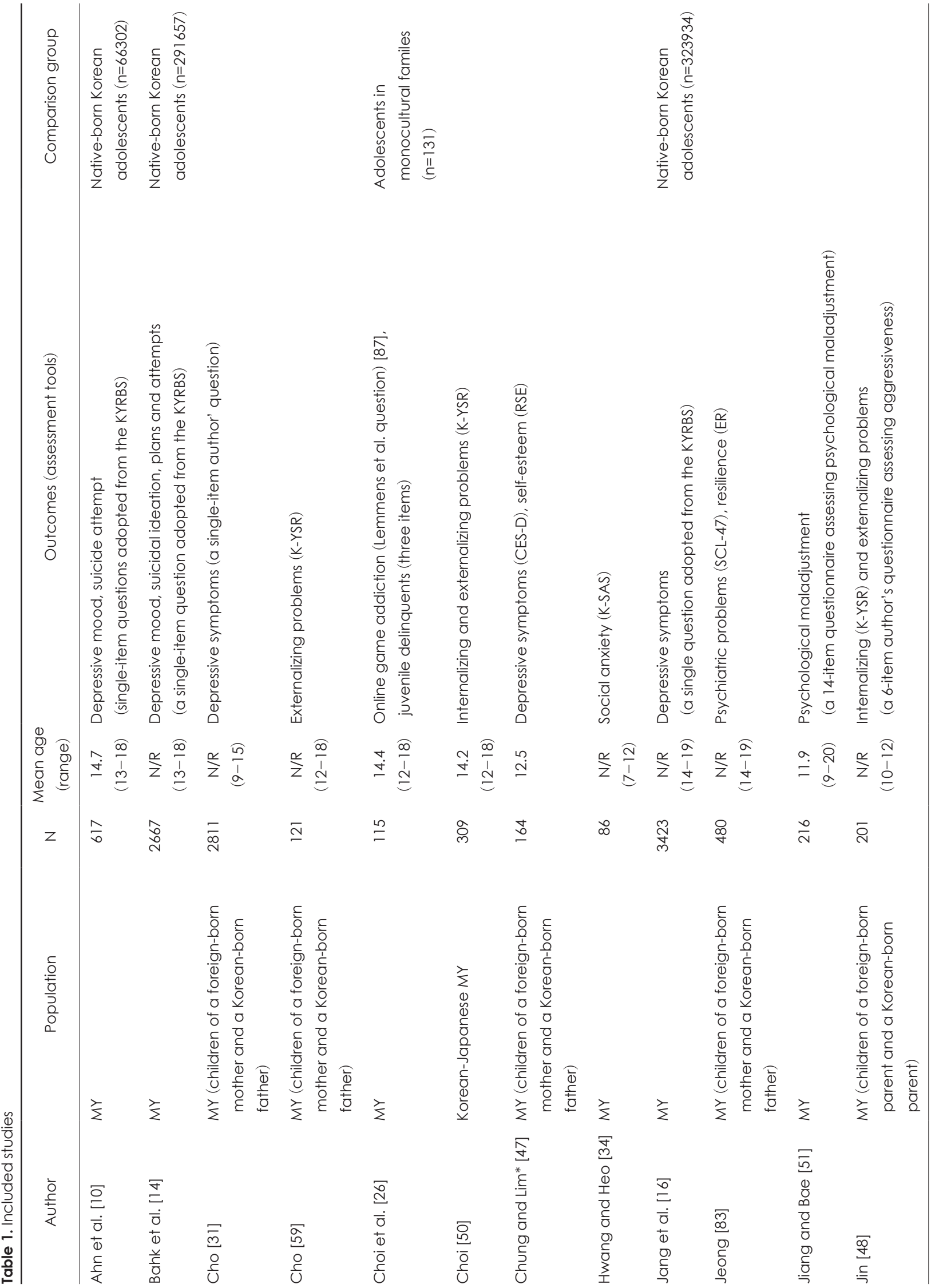




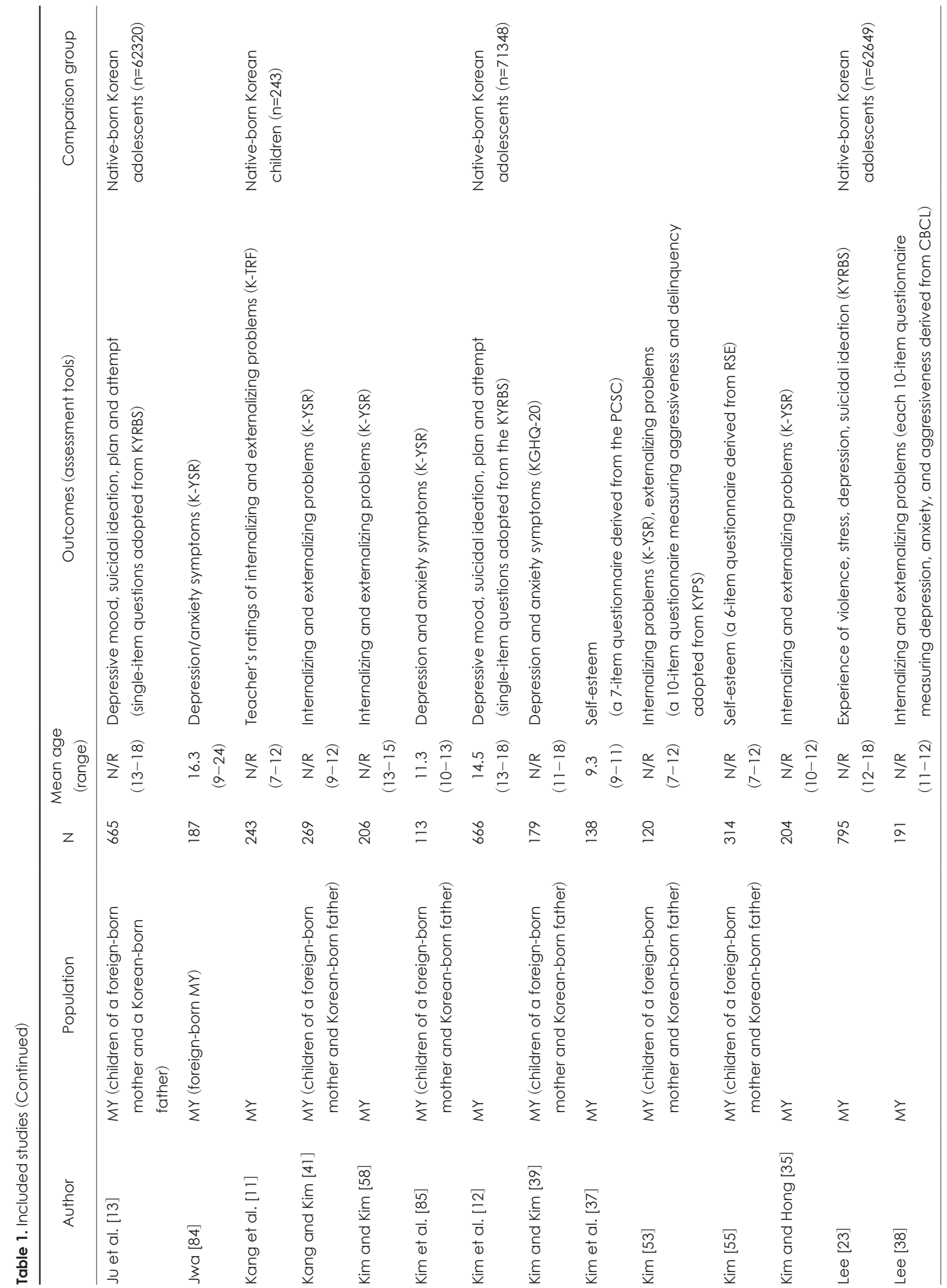




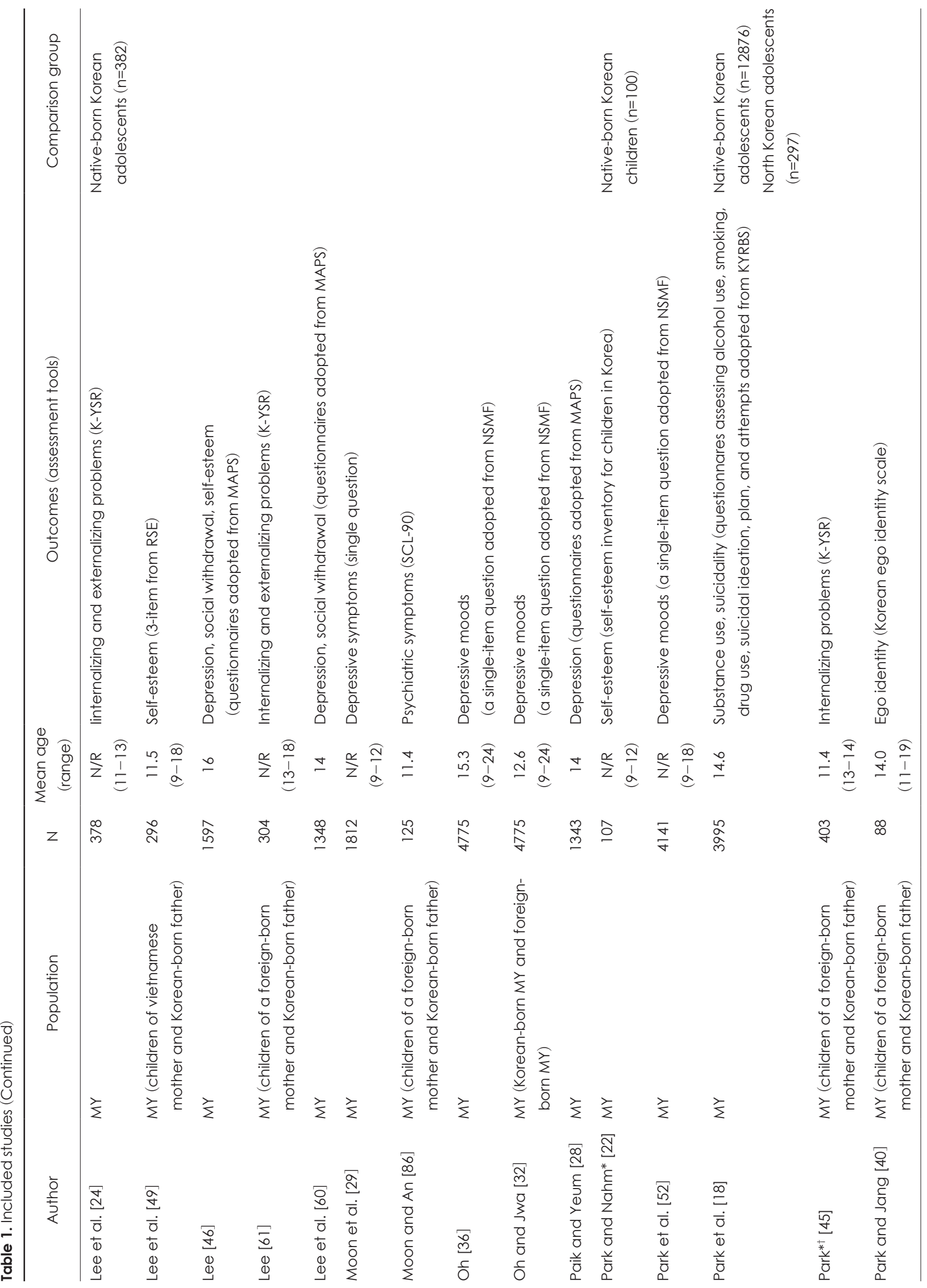




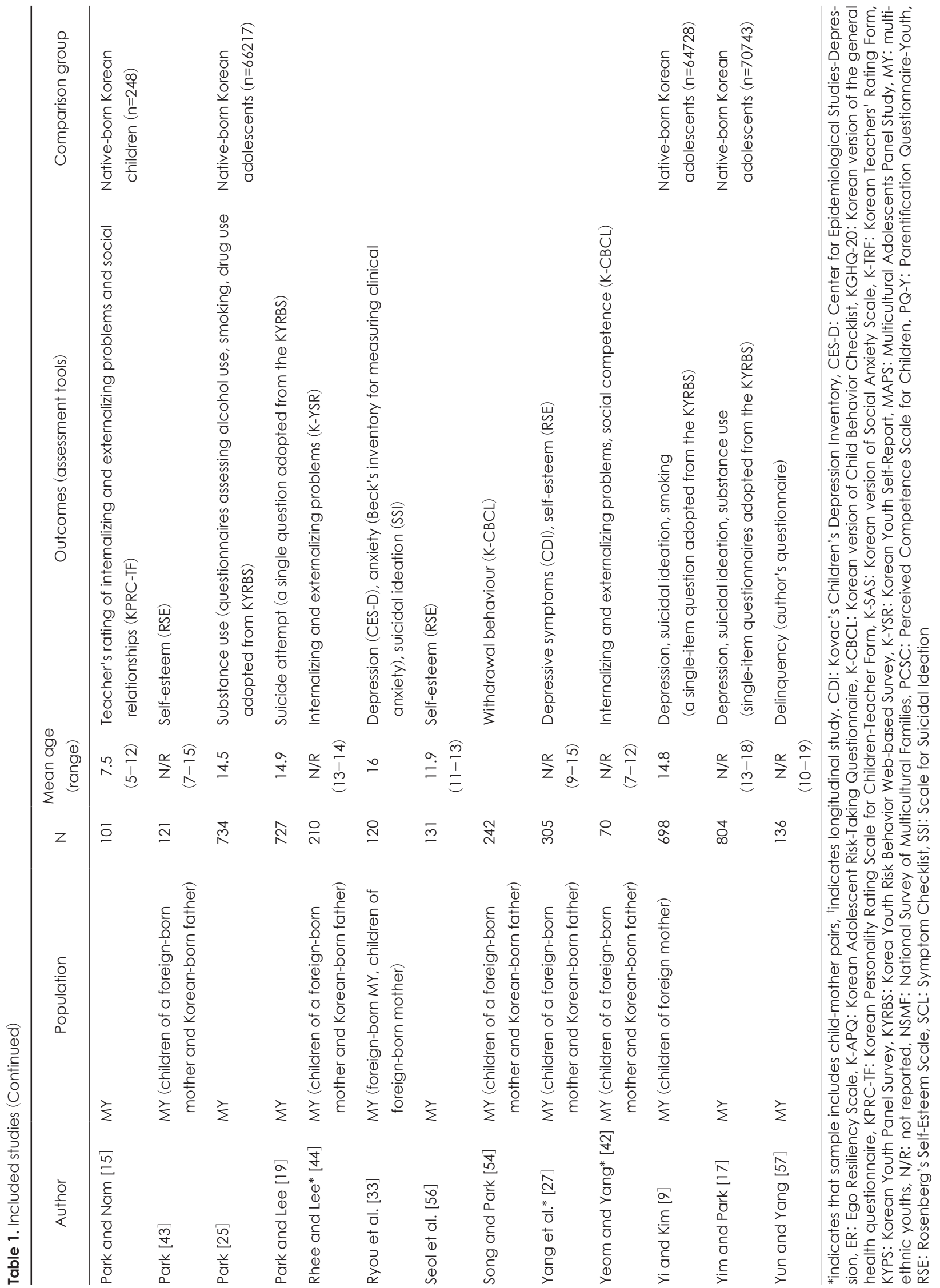


port poorer self-image and higher perceived stress than do native-born children across multiple domains, including appearance, academic performance, and peer and family relationships [20-23].

Externalizing problems include diverse behavioral symptoms, such as aggressive and hyperactive behaviors and delinquencies, including smoking and drinking. One study noted that young MY, between the ages of 5 and 12 years, were more likely to engage in hyperactive behaviors, as rated by their teachers, in comparison to native-born peers [15]. Another study showed that young MY between the ages of 11 and 13 years had higher scores on externalizing problems including delinquency and aggression compared to their monocultural peers [24]. For adolescent MY, studies have focused more on delinquent behaviors. In general, MY display a high rate of smoking or substance use $[9,10,17,18]$, but behaviors differ as a function of the multicultural family type. Compared with native-born adolescents, MY with foreignborn fathers or foreign-born parents were more likely to smoke or use drugs. On the contrary, MY with foreign-born mothers were less likely to smoke or use alcohol [25]. Moreover, adolescents from multicultural families had higher game addiction factor and mood modification scores than those from monocultural families. However, there was no significant difference in juvenile delinquency between MY and NKRY adolescents [26].

\section{Associated environmental factors}

\section{Sociodemographic factors}

Socioeconomic positions, such as low family income [19,2729], non-desirable occupation of the father [30], and low parental education level $[29,31]$ have been linked to increased mental health risks, including depressive symptoms, suicide attempts, and problematic alcohol use, among MY. Moreover, one's living arrangement was noted as a significant factor; MY who were not currently living with their parents were at a high risk of attempting suicide [19].

Family-related demographic factors are closely associated with the mental health of MY. MY with foreign-born fathers or foreign-born parents are at a greater risk of internalizing and externalizing problems, including depressive moods and suicidal behaviors, than MY with foreign-born mothers $[14,19]$ or native Korean parents [16,18]. Moreover, foreign-born MY who migrated to South Korea experience a higher rate of social discrimination and peer victimization, and thus, report greater depressive moods as compared to Korean-born MY $[32,33]$. Specifically, family separation during the immigration process is a significant risk factor; the longer the separation from parents, the higher the level of depression and anxiety symptoms as well as suicidal ideation [33].

\section{Familial factors}

Family relationship quality, which is assessed as family cohesion, support, communication, and subjective satisfaction, also plays an important role in the overall psychological adaptation of MY. It decreases mental health risks such as depression, anxiety, and suicidal ideation [28,31,33-36] and improves self-esteem [37]. In contrast, the risk for depression was high among MY who spent less time conversing with their fathers and those whose parents showed a low degree of interest in them [29]. Moreover, verbal or physical violence between parents or toward young MY predicted aggressiveness, as well as depressive and anxiety symptoms [38].

Positive parenting, which involves the adoption of an open communication style [39] and consistent and less authoritarian parenting [40], was associated with better mental health (e.g., decreased depression and anxiety and a better-developed identity) among MY. The extent of a mother's acceptance of her children's emotions was also associated with the self-esteem of young MY [22]. In addition, parentification, which is the process whereby a child is obliged to act as a parent to their own parent or sibling, was negatively correlated with both externalizing and internalizing problems among young MY, but not among monocultural family youth. This suggests that family strengths, shame, and self-differentiation are significant mediators between parentification and the mental health of young MY [24].

In addition to the influence of the mother-child relationship [41], the mother's psychosocial adaptation also affects internalizing and externalizing problems in MY [42]. Particularly, for MY with foreign mothers, the ease or difficulty with mother's sociocultural adaptation, acculturative stress, and perceived discrimination in South Korea canpredict low selfesteem, depressive symptoms, and behavioral problems among MY [27,40,42-45]. One longitudinal study noted that acculturative stress and marginalization (from both host and home cultures) of foreign mothers were associated with the decreased multicultural acceptance of MYs, which also predicted greater depressive symptoms and social withdrawal three years later. Conversely, successful integration of a mother's original and host culture predicted low likelihood of the occurrence of depression and social withdrawal in children [46]. In a mediation study, a mother's perceived discrimination and acculturative stress influenced the internalizing symptoms of the MY via an increase the mother's depressive symptoms [47]. Proficiency in the Korean language was found to have a positive effect [47-49]. Given the significant association between Korean language ability and both internalizing and externalizing symptoms $[29,35,36,50]$ and psychological 
maladjustment of MY [51], MY whose mothers have difficulty learning the Korean language may have poorly developed language ablities, which may indirectly influence their adaptation.

\section{Social relationships}

The influences of other social relationships have been reported. Discrimination from friends, teachers, relatives, and even strangers, has been associated with heightened internalizing and externalizing problems $[31,35,50,52,53]$, withdrawal behaviors [54], and decreased self-esteem among MY [55]. One mediation study suggested that experiencing social discrimination may adversely affect the self-image of MY since it leads to the internalization of stigma [56]. Another study reported that dual identity partially mediates the effect of social rejection on withdrawal behaviors [54]. Problematic relationships with peers have deleterious psychosocial impacts such as a high risk for depressive moods, suicide ideation or attempts, and delinquent behaviors $[12,23,29,31$, $53,57]$. Moreover, stress resulting from conflicts with teachers has a significant impact on suicide attempts by MY when compared to other stressors [19].

Positive aspects of social relationships can also enhance MY adaptation. In general, perceived social support is associated with decreased internalizing symptoms [53,58], delinquent behaviors [57], improved self-esteem [27], and a more developed identity in MY [40]. Specifically, support at school from peers, teachers, and after-school teachers has been independently associated with low levels of depressive symptoms $[28,33]$. A path analysis further noted that social support acts as a buffer against stresses from discrimination or problematic peer relationships, and attenuates the psychological impact of such distress [53].

\section{Cultural adjustment}

Cultural adjustment can be a psychological challenge for MY when one has to navigate one's Korean culture with that of a foreign-born parent(s). The difficulty associated with cultural adaptation among MY has been linked to internalizing and externalizing problems $[41,48]$. A number of mediation studies noted that stress associated with cultural adaptation among MY influences internalizing problems by decreasing one's sense of identity [58]. Additionally, stress associated with cultural adaptation predicts externalizing problems (e.g., delinquency and aggressiveness) via a increase difficulty in school adaptation [59]. One moderation study showed that acculturation stress in MY affects the levels of psychological maladjustment whereas resilience moderates the relationship between acculturation stress and the levels of psychological maladjustment [51]. While marginalization by both the Korean culture and that of foreign parents is associated with greater depressive symptoms and social withdrawal [31,60], bicultural acceptance [27,60], bicultural efficacy [48], and a well-established ethnic identity $[49,50]$ are consistently linked to better psychological adaptation. In another study, the degree of the perception of an individual as Korean by others, rather than one's own self-perception, is associated with overall internalizing (social withdrawal, anxiety, and depression) and externalizing problems [61], highlighting the significance of the social perception of MY.

\section{DISCUSSION}

This review addressed a range of mental health risks among children from multicultural families. We aimed to, first, compare the mental health outcomes of MY with those of NKRY and, second, identify multiple layers of environmental factors that may facilitate or inhibit psychological adjustment (Fig. 2).

Ethnic minority status and relevant socioeconomic disadvantages pose mental health risks for MY $[62,63]$. Consistent with the results of studies on ethnic minorities in other countries [64,65], much empirical evidence supports disparities in mental health outcomes between MY, who are at a higher risk for emotional and behavioral problems, and their native-born counterparts. However, it should be noted that risks/ outcomes vary across studies. Differences may be attributed to the heterogeneous outcome variables or samples examined across studies. Specifically, large-scale studies reveal more than a two-fold risk for suicidal behavior among MY $[14,19]$ compared to NKRY. This suggests the need for early preventive interventions.

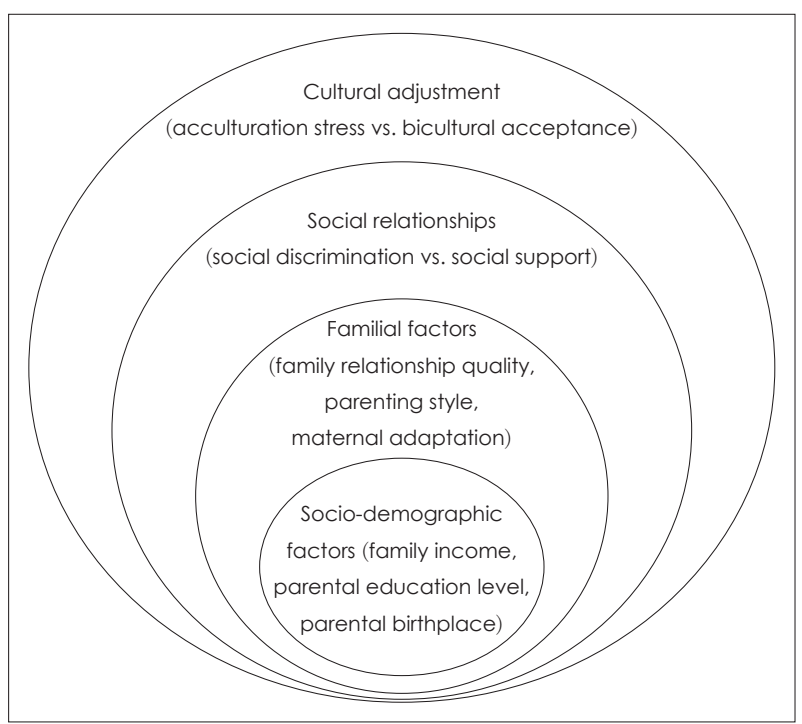

Fig. 2. Multiple layers of contextual factors affecting multiethnic youths mental health. 
Proximal family variables were the most studied environmental factors for assessing associations with psychological mental health in MY. Among family-related mental health risks, separation from parents is the most consistent predictor of mental health issues, which include depression, anxiety, and suicidal ideation and attempts $[19,33]$. This is especially the case for immigrant MY, who experience family separation during the immigration process, which may have adverse mental health effects on them [33]; thus, the impact of long-term mental health on future integration in South Korea should be carefully considered. Moreover, poor family relationships and domestic violence predict a high risk for mental health issues in MY [38]. Previous studies involving immigrant women who married Korean men showed higher marital distress in multicultural families than in native Korean families [66]. This marital distress often presented as a high prevalence of domestic violence. Robust social protective systems are needed for MY who do not have familial support for successful multicultural adjustment.

Limited education and income opportunities partially cause ethnic disparities in access to mental health resources $[67,68]$. These social disadvantages pose risks for deleterious psychosocial adaptation among children, as well [69,70]. Mental health outcomes among MY in South Korea are also influenced by the parents' ethnicity and socioeconomic status [19,27,30,31]. Moreover, maternal psychosocial problems, notably depression and cultural maladjustment, increase the mental health risks of children. This is consistent with the well-established notion of "intergenerational transmission" of maternal mental health $[71,72]$. Given the positive influence of helpful social support provided for foreign-born mothers and for the adjustment of MY [73], social support systems for first-generation immigrants could have many secondary effects on the mental health of their children.

Social support and belonging are important for youth who feel isolated from ethnic majority groups [74]. Social discrimination has deleterious effects on the mental health of MY. However, social support can act as a buffer against social adversity [53]. Our review particularly highlights the major role of MY relationships, including peer and teacher relationships, at school. Previous studies noted that MY experience more difficulty in overall adjustment at school compared to native-born youths. The parameters for adjustment include relationships with teachers and peers, as well as academic adaptation and rule observation [20,21]. In one case-control study, MY reported more problems with peer relationships. They feel excluded or are dissatisfied with their peer group compared to their native-born peers [22]. Furthermore, studies that used data on Korean youth showed that MY were three to five times more likely to report being victims of school violence $[10,12,23]$, and specifically those with foreign-born mothers were 4.1 times, and those with foreign-born fathers were 17.4 times at a higher risk of victimization respectively [75]. Given the critical role of peer relationships in the psychological adjustment of youth later in life [76,77] and the adverse effect of peer bullying on future psychopathology [78], interventions to enhance school connectedness and peer relationships are necessary for healthy MY adjustment.

The integration of distinct cultures and ethnic identities is another important challenge for MY. MY experience difficulties coping with being dissimilar to the majority of their peers. In addition to cultural differences, the perceived differences in appearance between MY and their peers contribute to poor school adaptation [79], which can adversely affect psychological wellbeing [29]. Psychological interventions could help foster more effective coping strategies. For instance, a social-belonging intervention in the United States yielded long-term positive effects on the health and academic achievement of minority students. This was accomplished by monitoring the changes in the perception of youths regarding the social consequences of one's minority status [80]. Given the effect of such societal perceptions on adaptation [61], educating native-born youths to accept ethnic and cultural differences is necessary.

\section{Limitations}

Our systematic review had a few notable limitations. First, a meta-analysis could not be conducted given the extensive heterogeneity in sample demographics (e.g., age, parental origin), outcome variables, and measurements. Second, as this review only included published articles, a publication bias could be present. Thus, conclusions regarding the true nature of MY maladjustment should take these limitations into consideration.

\section{Suggestions for future research}

Future studies should investigate how multiple risk and protective factors work together to impact outcomes. Although several studies have identified simple and correlational relationships between each factor and MY mental health outcomes, the effect of any individual factor cannot be fully understood without examining the complex interactions between variables [81]. Furthermore, a prospective study to investigate long-term mental health outcomes and causal relationships between variables over time is required. Lastly, given the disparities in the use of services among MY in other countries [82], the utilization of mental health services by MY must be explored. Future work is needed to address the gap between service needs and service utilization in order to tackle relevant psychosocial barriers. 


\section{CONCLUSIONS}

We reviewed 54 studies to compare MY's mental health outcomes with those of NKRY's and to identify multiple layers of relevant environmental factors. In conclusion, empirical evidence indicated that MY have relatively heightened risks for emotional and behavioral problems. The multiple layers of contextual factors including socio-demographic factors, familial factors, social relationships, and cultural adjustment were identified and noted. Future studies must elucidate the complex interplay between multiple risk and protective factors and the long-term adaptation and mental health service utilization of MY.

\section{Acknowledgments}

This work was supported by a clinical research grant (No. 201807) from the National Center for Mental Health, Republic of Korea.

\section{Conflicts of Interest}

The authors have no potential conflicts of interest to disclose.

\section{REFERENCES}

1) Castles S, De Haas H, Miller MJ. The age of migration: international population movements in the modern world. 5th ed. Basingstoke: Palgrave Macmillan;2013.

2) Ministry of Gender Equality and Family. An analysis on the national survey of multicultural families 2015 (oiginal data in Korean). Seoul: Ministry of Gender Equality and Family;2016.

3) Ministry of Gender Equality and Family. 2018 National Survey on the Multicultural Families. Seoul: Ministry of Gender Equality and Family;2019.

4) Phinney JS. Ethnic identity in adolescents and adults: review of research. Psychol Bull 1990;108:499-514.

5) Okazaki S. Impact of racism on ethnic minority mental health. Perspect Psychol Sci 2009;4:103-107.

6) Smedley BD, Myers HF, Harrell SP. Minority-status stresses and the college adjustment of ethnic minority freshmen. J High Educ 1993;64:434-452.

7) Berry JW, Kim U. Acculturation and mental health. In: Dasen PR, Berry JW, Sartorius N, editors. Health and cross-cultural psychology: towards applications. Newbury Park: Sage;1988. p.207-236.

8) Bronfenbrenner U. The ecology of human development. Cambridge: Havard University Press; 1979.

9) Yi Y, Kim JS. Korean adolescents' health behavior and psychological status according to their mother's nationality. Osong Public Health Res Perspect 2017;8:377-383.

10) Ahn IY, Seo J, Lee D, Lee SJ, Cha B, Lee CS, et al. Emotional characteristics of adolescents in monocultural and multicultural families in Korea. J Korean Acad Child Adolesc Psychiatry 2016;27: 306-312.

11) Kang JH, Yeo TC, Kim JC, Kim JH, Im JY. Comparison of sociality between children from multi-cultural families and children from non-multi-cultural families: latent mean analysis in behavioral problems and social abilities. Journal of Education \& Culture 2013;19: 31-62.

12) Kim JM, Kong BG, Kang JW, Moon JJ, Jeon DW, Kang EC, et al. Comparative study of adolescents' mental health between multicultural family and monocultural family in Korea. J Korean Acad Child Adolesc Psychiatry 2015;26:279-287.

13) Ju HO, Park SY, Lee J. Mental health and health risk behaviors of multicultural adolescents according to their mothers' native country: using data from the 11th (2015) Korea youth risk behavior webbased survey 2015. Child Health Nurs Res 2017;23:101-110.

14) Bahk J, Kim AM, Khang YH. Associations of multicultural status with depressive mood and suicidality among Korean adolescents: the roles of parental country of birth and socioeconomic position. BMC Public Health 2017;17:116.

15) Park JH, Nam JS. The language development and psychosocial adjustment of multicultural children. Stud Korean Youth 2010;21: 129-152.

16) Jang J, Park EC, Lee SA, Choi Y, Choy YS, Kim W, et al. Association between parents' country of birth and adolescent depressive symptoms: the early stages of multicultural society. J Korean Med Sci 2018;33:e116.

17) Yim SY, Park MH. Behaviors and mental health of adolescents in multi-cultural families compared to general families. Journal of The Korean Data Analysis Society 2014;16:1641-1651.

18) Park S, Lee M, Park SJ, Lee MG. Health risk behaviors and psychological problems among South Korean, North Korean, and other multicultural family adolescents (2011-2016). Psychiatry Res 2018;268:373-380.

19) Park S, Lee Y. Factors that affect suicide attempts of adolescents in multicultural families in Korea. Int J Environ Res Public Health 2016;13:E1184.

20) Hwang SY, Rho BI. A study on the factors that influence satisfaction with school life of children from multicultural families. Korea Academy of Care Management 2015;15:51-76.

21) Kim AY, Kim SI. Comparisons of psychological factors related to school adjustment between children from international marriage families and from general families. Korean Journal of Educational Psychology 2011;25:853-873.

22) Park E, Nahm E. Comparative research with general family: relation between accommodation attitude of emotional expression by multi culture family mother, children's peer relation and self-esteem. Journal of the Korean Association of Psychotherapy 2011;3: 53-68.

23) Lee E. Effects of school violence on depression and suicidal ideation in multicultural adolescents. Iran J Public Health 2019;48: 262-269.

24) Lee JS, Kim JM, Ju AR. A structural analysis on the effects of children's parentification in multicultural families on their psychological maladjustment - comparison with children in monocultural families. Journal of the Korea Institute of Youth Facility and Environment 2018;16:117-130.

25) Park S. Substance use and sexual behaviors of adolescents in multicultural families in Korea. Psychiatry Investig 2015;12:466-473.

26) Choi C, Hums MA, Bum CH. Impact of the family environment on juvenile mental health: eSports online game addiction and delinquency. Int J Environ Res Public Health 2018;15:E2850.

27) Yang SY, Park SK, Kim MS. Effects of bicultural characteristics and social capital on psycological adaptation. Journal of the Korea Contents Association 2013;13:270-282.

28) Paik JG, Yeum DM. A latent profile analysis on depression and ego-resiliency of adolescents in multi-cultural families. Journal of Multicultural Society 2018;11:295-319.

29) Moon SH, Lee MK, Lee MJ, Shim HJ, Cho HH. Factors influencing the experience of depression among school-aged children from multicultural families. Child Health Nurs Res 2018;24:434442.

30) Baik J, Kim J, Yu Y. A study on affecting factors on school resilience of adolescent from multicultural families. Youth Facility \& Environment 2013;11:157-170.

31) Cho R. Exploring the acculturation profiles and adaptation of children in multiethnic families in South Korea. Asian and Pacific Migration Journal 2016;25:245-274. 
32) Oh S, Jwa $\mathrm{H}$. The factors affecting on depression of multi-cultural families adolescents and immigrant adolescents. Journal of School Social Work 2015;32:385-412.

33) Ryou B, Choi J, Sohn Y, Kim K. Understanding of migration experiences and mental health among Korean immigrant youth. Journal of the Korean Society of Child Welfare 2017;58:231-262.

34) Hwang M, Heo G. The effect of parents attachment on social anxiety to multi-culture children link to the northeast Asian. Journal of North-East Asian Cultures 2010;23:277-287.

35) Kim SJ, Hong $\mathbf{C H}$. The effect of discrimination experience and language problems on psychosocial adjustment in children with multi-cultural family: the moderating effect of ego-resilience and family strengths. Korean J Youth Stud 2017;24:195-211.

36) Oh S. The study on the eco-systemic variables affecting multicultural family adolescents' depression. Journal of Community Welfare 2016;56:1-27.

37) Kim MY, Lim JY, Chung GH. Effects of Korean proficiency and parent-child cohesion on self-esteem and acculturation among children from multicultural families. J Korean Acad Nurs 2012;42: 879-888.

38) Lee HB. The influence of domestic violence and child abuse internalization and externalization in multicultural families child. J Welf Couns Educ 2014:3:55-79.

39) Kim MK, Kim HY. The effects of psychological characteristics, parent-child relationship, and coping strategies on school adjustment of multicultural family adolescents. Korean Journal of Family Welfare 2015;20:367-385.

40) Park JW, Jang JH. The environmental and psychological factors influencing the ego identity of teenagers from multicultural families. Korean Journal of Youth Studies 2014;21:133-154.

41) Kang Y, Kim B. The relationships between the attachment of multicultural family children to mothers and theirs psychosocial adjustments: the intervening effects of acculturation stresses and negative coping mechanisms. Korea Journal of Youth Counseling 2013;21:19-42.

42) Yeom M, Yang S. A Study on the maternal cultural and emotional factors influencing the children's mental health in multicultural families. J Korean Acad Psychiatr Ment Health Nurs 2014;23:1-11.

43) Park M. Mothers' Korean proficiency and children's self-esteem in multi-cultural families. Health and Social Welfare Review 2010; 30:193-218.

44) Rhee JY, Lee JY. The influence of stress for cultural adaptation of mothers of multicultural families on children's emotional and behavioral problems. Counseling Psychology Education Welfare 2016; 3:19-27.

45) Park HS. Mediated effects of acculturative stress and maternal parenting stress on internalized problems of children in multicultural families: focused on the mediating role of mothers' depression. Journal of School Social Work 2014;27:353-376.

46) Lee S. A study of longitudinal changes and relevant factors of muticultural acceptability attitudes amongst multiethnic adolescents. Studies on Korean Youth 2018;29:179-208.

47) Chung GH, Lim JY. Marriage immigrant mothers' experience of perceived discrimination, maternal depression, parenting behaviors, and adolescent psychological adjustment among multicultural families in South Korea. Journal of Child and Family Studies 2016;25:2894-2903.

48) Jin EY. Mediating effect of bicultural competence in the relationship between acculturative stress of children in multi-cultural families and psychosocial adjustment: focusing on gender difference. Journal of School Social Work 2015;32:303-326.

49) Lee J, Cheon YM, Wei X, Chung GH. The role of ethnic socialization, ethnic identity and self-esteem: implications for FBI-ethnic adolescents' school adjustment. Journal of Child Family Studies 2018;27:3831-3841
50) Choi WS. Personal characteristics, ethnic identity, experience of discrimination, self-esteem, and problem behavior of Korean-Japanese multicultural adolescents. Korean Journal of Family Welfare 2012;17:49-71.

51) Jiang H, Bae EK. The relationship between acculturation stress of adolescents in multicultural families and their psychological maladjustment: focus on the moderating effects of resilience. Journal of the Korean Society of Child Welfare 2018;62:131-164.

52) Park GR, Son I, Kim SS. Perceived ethnic discrimination and depressive symptoms among biethnic adolescents in South Korea. J Prev Med Public Health 2016;49:301-307.

53) Kim SG. The psycho-social adaptation among children of multicultural families. Korean Journal of Youth Studies 2011;18:247-272.

54) Song SR, Park M. Social rejection and withdrawal behaviors experienced by children in multicultural families: the mediating role of dual identity. Journal of Future Social Work Research 2018;9: 65-96.

55) Kim SG. A study on influencing factors on self-esteem of multicultural families children in Korea. Korean Journal of Youth Studies 2012;19:109-128.

56) Seol KO, Hwang D, Sim J. Multicultural children's perceived discrimination, internalized stigma and self-esteem: a moderated mediating effect of ethnic identity. Korean Journal of Developmental Psychology 2018;31:71-90.

57) Yun G, Yang M. A study on influencing to prediction risk factors of the delinquency experience on juvenile of multicultural. Korean Police Studies Review 2015;14:313-338.

58) Kim EG, Kim JN. The relationships between multi-cultural adolescents' acculturation stress and psycho-social adjustment: the mediating effect of ego-identity and the moderating effect of perceived social support. Multicultural Education Studies 2016;9:21-43.

59) Cho Y. Externalizing behaviors in multicultural children of immigrant mothers: a mediation model. Journal of Family Issues 2017; 38:904-920.

60) Lee Y, Park R, Lee S. A study about bicultural acceptance attitude and psychological adaption, school adaption of adolescents in multicultural family. Journal of Education \& Culture 2017;23:347-372.

61) Lee YJ. A study on the risk factors influencing psychosocial adjustment of a multicultural family adolescent. Korean Journal of Family Welfare 2009;14:103-119.

62) Alegria M, Vallas M, Pumariega AJ. Racial and ethnic disparities in pediatric mental health. Child Adolesc Psychiatr Clin N Am 2010;19:759-774.

63) Alegría M, Green JG, McLaughlin K, Loder S. Disparities in child and adolescent mental health and mental health services in the U.S. New York: William T. Grant Foundation;2015.

64) Anderson ER, Mayes LC. Race/ethnicity and internalizing disorders in youth: a review. Clin Psychol Rev 2010;30:338-348.

65) Brown JS, Meadows SO, Elder GH. Race-ethnic inequality and psychological distress: depressive symptoms from adolescence to young adulthood. Dev Psychol 2007;43:1295-1311.

66) Choi GY, Byoun SJ. Domestic violence against migrant women in South Korea: addressing the needs of a uniquely situated victim population in domestic violence policy. International Social Work 2014;57:645-660.

67) Karlsen S, Nazroo JY. Relation between racial discrimination, social class, and health among ethnic minority groups. Am J Public Health 2002;92:624-631.

68) Williams DR, Yan Yu, Jackson JS, Anderson NB. Racial differences in physical and mental health. J Health Psychol 1997;2:335351.

69) Portes A, MacLeod D. Educational progress of children of immigrants: the roles of class, ethnicity, and school context. Sociology of Education 1996;69:255-275.

70) Bøe T, Øverland S, Lundervold AJ, Hysing M. Socioeconomic sta- 
tus and children's mental health: results from the Bergen Child Study. Soc Psychiatry Psychiatr Epidemiol 2012;47:1557-1566.

71) Hammen C, Shih JH, Brennan PA. Intergenerational transmission of depression: test of an interpersonal stress model in a community sample. J Consult Clin Psychol 2004;72:511-522.

72) Beardslee WR, Versage EM, Gladstone TR. Children of affectively ill parents: a review of the past 10 years. J Am Acad Child Adolesc Psychiatry 1998;37:1134-1141.

73) Han S, Xue Y, Cheng C, Park Y. Relationships among immigrant women's perceived social support, acculturation stress, and their children's school adjustment. Korean Journal of Educational Methodology Studies 2017;29:1-23.

74) Kia-Keating M, Dowdy E, Morgan ML, Noam GG. Protecting and promoting: an integrative conceptual model for healthy development of adolescents. J Adolesc Health 2011;48:220-228.

75) Park S, Lee Y, Jang H, Jo M. Violence victimization in Korean adolescents: risk factors and psychological problems. Int J Environ Res Public Health 2017;14:E541.

76) Parker JG, Asher SR. Peer relations and later personal adjustment: are low-accepted children at risk? Psychol Bull 1987;102:357-389.

77) Hymel S, Rubin KH, Rowden L, LeMare L. Children's peer relationships: longitudinal prediction of internalizing and externalizing problems from middle to late childhood. Child Development 1990;61:2004-2021.

78) Arseneault L, Bowes L, Shakoor S. Bullying victimization in youths and mental health problems: 'much ado about nothing'? Psychol Med 2010;40:717-729.

79) Kim S, Jeon S. School adaptation according to multicultural characteristics of children from multicultural families. The Study of
Child-Family Therapy 2012;10:53-67.

80) Walton GM, Cohen GL. A brief social-belonging intervention improves academic and health outcomes of minority students. Science 2011;331:1447-1451.

81) Kraemer HC, Stice E, Kazdin A, Offord D, Kupfer D. How do risk factors work together? Mediators, moderators, and independent, overlapping, and proxy risk factors. Am J Psychiatry 2001;158: 848-856.

82) Garland AF, Lau AS, Yeh M, McCabe KM, Hough RL, Landsverk JA. Racial and ethnic differences in utilization of mental health services among high-risk youths. Am J Psychiatry 2005;162:13361343.

83) Jeong M. The effect of multicultural adolescent's self-resilience on mental health. Korean Journal of Youth Studies 2015;22:137162.

84) Jwa DH. A research on the psycho-social adaptation characteristics of immigrant youths based on nationality and acculturation types. Korean Journal of Youth Studies 2014;21:97-126.

85) Kim HM, Won SJ, Choi SH. Experiences of discrimination and psychological distress of children from multicultural families: examining the mediating effect of social support. Korean Journal of Social Welfare Studies 2011;42:117-149.

86) Moon SH, An HJ. Anger, anger expression, mental health and psychosomatic symptoms of children in multi-cultural families. J Korean Acad Psychiatr Ment Health Nurs 2011;20:325-333.

87) Lemmens JS, Valkenburg PM, Peter J. Development and validation of a game addiction scale for adolescents. Media Psychology 2009;12:77-95. 